\title{
LA TRANSICIÓN SOLUTRENSE-MAGDALENIENSE EN LA CUEVA DE EL CIERRO (RIBADESELLA, ASTURIAS, ESPAÑA)
}

\author{
Solutrean-Magdalenian transition in El Cierro Cave \\ (Ribadesella, Asturias, Spain)
}

\author{
David Álvarez-Alonso ${ }^{1}$ y María de Andrés-Herrero ${ }^{2}$
}

Recibido el 8 de marzo de 2013. Aceptado el 12 de septiembre de 2013

Resumen. La cueva de El Cierro (Ribadesella, Asturias, España) está situada en un espolón calizo ubicado en la plataforma kárstica que va desde Sardeo a Ardines, en el mismo lugar en el que se encuentra también la cueva de Les Pedroses, que cuenta con manifestaciones artísticas que han sido asignadas al Magdaleniense inferior (Jordá 1975). Este enclave está muy próximo a otros yacimientos solutrenses de relevancia, como es el caso de Cova Rosa, o magdalenienses como Tito Bustillo. El Cierro fue excavado por primera vez por F. Jordá Cerdá en 1959, continuando sus investigaciones en este yacimiento a partir de 1976 junto con A. Gómez Fuentes. Entre ambas intervenciones, en 1969, G. A. Clark realizó una toma de muestras en el conchero superior. Con este trabajo se pretende realizar una contextualización nivel 4 de El Cierro a partir de la revisión de los materiales procedentes de la primera intervención de F. Jordá, en el contexto de la transición Solutrense-Magdaleniense en la Región Cantábrica.

Palabras clave: Badeguliense, conjunto lítico, estratigrafía, región cantábrica, Solutrense, Magdaleniense.

Abstract. El Cierro cave (Ribadesella, Asturias, Spain) is located in a spur of limestone in a karstic platform ranging from Sardeo to Ardines, in the same place in which we also find Les Pedroses cave, with rock art assigned to Lower Magdalenian (Jordá 1975). This site, which has provided an interesting sequence to end of the Solutrean and Early Magdalenian, is very close to other relevant Solutrean sites, as Cova Rosa. F. Jordá Cerdá was the first researcher who excavated in El Cierro cave in 1959. He continued his research in this site with A. Gómez Fuentes since 1976. This paper aims to make a contextualization of Upper Cantabrian Solutrean from checking the materials of this site.

Key words: Badegoulien, cantabrian region, lithic assemblages, stratigraphy, Solutrean, Magdalenian.

(') Departamento de Prehistoria y Arqueología. UNED. Centro Asociado de Asturias. Avda. Jardin Botánico 1345. E-33203 Gijón (España). dalvarez@gijon.uned.es

(2)Departamento de Prehistoria y Arqueología. UNED. mariadandres@gmail.com 


\section{INTRODUCCIÓN}

En este trabajo nos centramos en analizar los materiales del nivel 4 de la cueva de El Cierro, procedentes de la excavación realizada por F. Jordá en 1959, y que ha sido atribuido tradicionalmente al Solutrense superior. Dichos materiales fueron estudiados por Straus (1983), único trabajo conocido hasta la fecha sobre este nivel, y se encuentran depositados en el Museo Arqueológico de Asturias.

El yacimiento fue excavado por vez primera por F. Jordá Cerdá, en una campaña de 15 dias entre los meses de junio y julio de $1959^{1}$. La zona en la que se realizaron las intervenciones arqueológicas se localiza en la entrada principal, en un área en la que gran parte del techo está derrumbado, y la metodología empleada fue la excavación del yacimiento por capas, considerando a cada una de ellas como una unidad estratigráfica o nivel. La actuación arqueológica se limitó a una limpieza y un pequeño sondeo, en una zona cuya extensión máxima no superaba los $2 \times 3 \mathrm{~m}$. Diez años después de la excavación de F. Jordá, Clark (1976) realizó una cata en un nivel de conchero, tomando de ahí una muestra que dio como resultado la siguiente datación: $10.400 \pm 500 \mathrm{BP}$. Posteriormente, en 1976, F. Jordá y A. Gómez Fuentes emprendieron nuevas excavaciones, actuando sobre el testigo dejado tras la primera intervención y cuyos resultados, al margen de alguna breve noticia (Gómez Fuentes y Bécares 1979), se encuentran inéditos.

La primera información que tenemos de esta cueva procede del Primer Symposium de Prehistoria de la Península Ibérica, celebrado en 1959, donde F. Jordá presentó un trabajo de gran importancia para la posterior investigación paleolítica cantábrica, sobre el complejo solutrense-magdaleniense (Jordá 1960). En esta publicación se menciona por vez primera la secuencia estratigráfica de El Cierro, y se da a conocer la existencia de un horizonte solutrense final en estrecha relación y continuidad con el Magdaleniense inferior suprayacente. Hasta el presente, todos los datos conocidos sobre esta cueva corresponden a diferentes estudios parciales realizados a partir de los materiales de la primera campaña de excavación. No existe, por tanto, un estudio global del yacimiento, si bien sus materiales arqueológicos fueron revisados por una serie de investigadores que estudiaron algunos de los niveles de esta cueva de manera independiente: Utrilla (1981), Bernaldo de Quirós (1982) y Straus (1983).

El primer corte estratigráfico conocido de El Cierro fue publicado por Utrilla (1981), quien realizó una unificación de las secuencias descritas por F. Jordá, Straus (1974), Clark (1976), y Gómez Fuentes y Bécares (1979) tras visitar la cueva durante el transcurso de las excavaciones de los años 70. En ella se documenta, de muro a techo, la presencia de un nivel Auriñaciense, un nivel del Solutrense superior final, un nivel Magdaleniense inferior, otro nivel Magdaleniense, suprayacente al anterior, y un conchero. Todos los investigadores anteriormente mencionados realizaron una revisión de la estratigrafía de El Cierro, centrándose en niveles diferentes. Así, Utrilla $(1976,1981)$ estudió las capas 3 y 4 (que equivalen a los niveles 2 y 3), asignadas al Magdaleniense; Straus $(1974 ;$ 1983), por su parte revisó la capa 5 (nivel 4) asociada a un nivel del Solutrense final; mientras que Bernaldo de Quirós (1982) analizó los materiales de las capas 6,7 y 8 , correspondientes, en principio, a los niveles auriñacienses. Por otra parte, la industria ósea del yacimiento ha sido publicada en varios trabajos (Utrilla 1981; Straus 1983), siendo el más completo el más reciente efectuado por Adán (1995).

Tras realizar un repaso a los materiales, trataremos de efectuar una contextualización del nivel 4 de este yacimiento en el panorama general del Cantábrico, dentro del marco existente en la actualidad para la transición entre el Solutrense y el Magdaleniense. A pesar de estar inéditos los resultados de las dos intervenciones arqueológicas efectuadas en El Cierro, esta cueva ha sido objeto de numerosas referencias en la investigación del Paleolítico superior final cantábrico, como prueba de su importancia en el debate sobre el final del Solutrense y los inicios del Magdaleniense en esta región. Es por ello que hemos considerado la necesidad de analizar este yacimiento, a la luz de los datos existentes en la actualidad en el contexto cantábrico.

\section{ENTORNO DEL YACIMIENTO Y SU ESTRATIGRAFÍA}

La cueva de El Cierro se localiza en El Carmen (Ribadesella), y más en concreto en el barrio de Fresno, a pocos kilómetros al SO de la desembocadura del Sella y de la línea de costa actual (Fig. 1). Se trata de una pequeña cavidad con dos bocas que comunican entre sí, encajada en el fondo de una dolina, en un pequeño macizo calcáreo que se destaca entre el paisaje circundante. El hábitat prehistórico de esta cueva y el de sus alrededores, se vio favorecido por un paisaje abierto y por su situación dentro de una pequeña depresión prelitoral que dista unos $2 \mathrm{~km}$ de la costa actual, en las cercanías del arroyo San Miguel, afluente del río Sella. Este entorno parece favorable, no sólo para el hábitat humano, sino también para la recolección de materias primas líticas necesarias para la elaboración del utillaje. Las idóneas condiciones de la zona para la ocupación humana, pueden constatarse por la proximidad a otros yacimientos de rele-

(') Archivo personal de D. Francisco Jordá Cerdá. D1-5 / Diario de excavación de la cueva de El Cierro, 1959. 


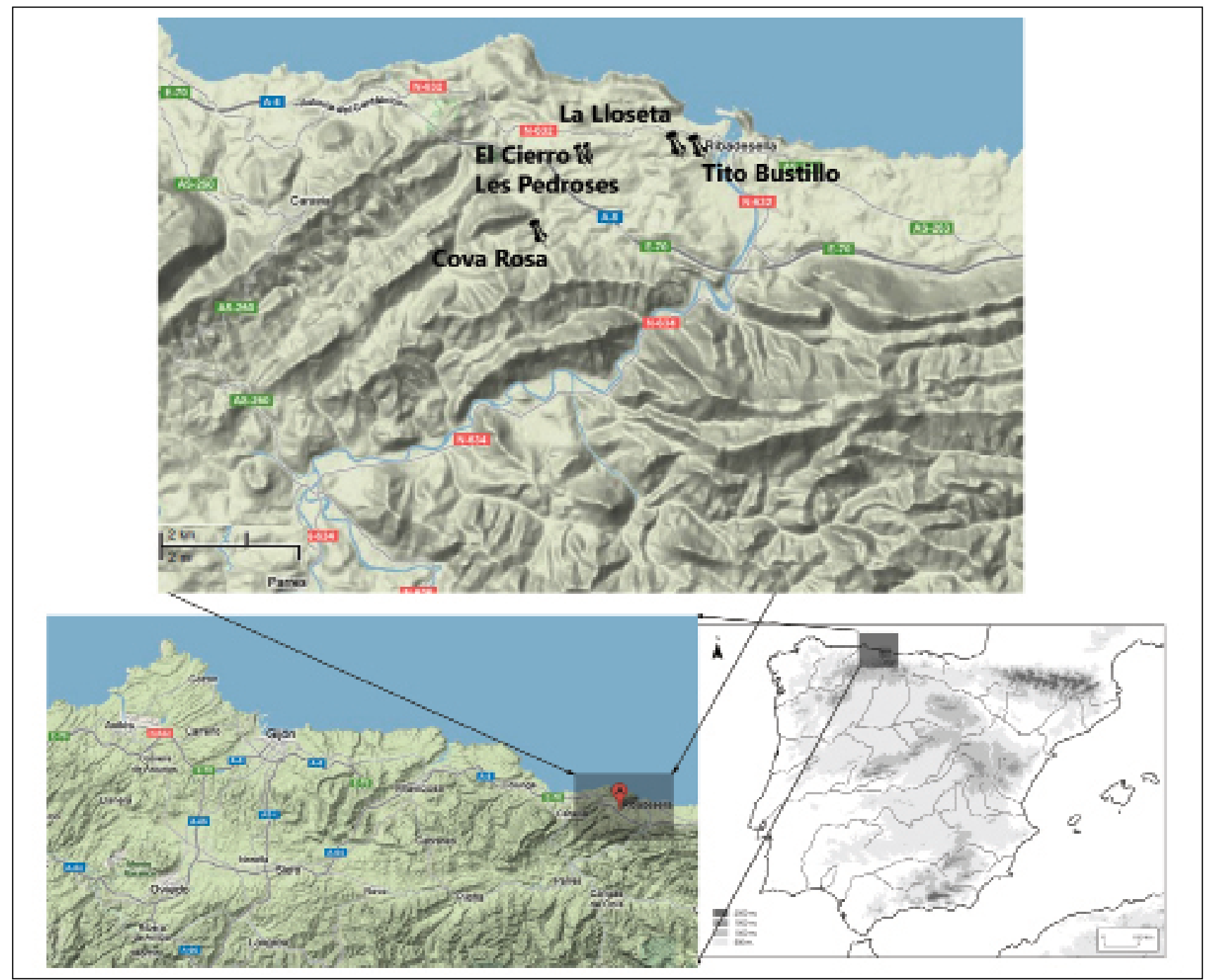

\ Figura 1. Mapa de localización de la cueva de El Cierro en el que se señalan otros yacimientos con niveles solutrenses y magdalenienses en el entorno inmediato.

vancia con ocupación humana desde el Solutrense hasta el final del Magdaleniense, como es el caso de Les Pedroses, Cova Rosa, La Lloseta o un gran centro de agregación magdaleniense como es Tito Bustillo.

F. Jordá realizó una subdivisión estratigráfica en capas. La relación que figura en su diario de excavación es la siguiente:

Capa $1^{\mathrm{a}}$ capa superficial

Capa $2^{\text {a }}$ capa negra. Magdaleniense superior

Capa $3^{\text {a }}$ capa de arcilla roja. Magdaleniense

Capa $4^{\text {a }}$ capa negra. Magdaleniense III

Capa 5 capa rojiza

Capa estéril

Capa $6^{a}$ capa arcilla roja. Poco material

Capa $7^{\text {a }}$ capa de ceniza, con rastro de hogares

F. Jordá indica en su diario, al referirse a la capa 5a: "En esta zona se observa en la base de la capa parduzca $5^{a}$ una negra de hogares más intensa. Decir, que podríamos suponer se comienza con un (aparece tachado Magdaleniense inferior) Solutrense final...". Por su parte, Straus (1974) al referirse a su estudio de los materiales del nivel 4 , menciona que la colección del Museo Arqueológico aparece con la sigla "Capa 5a. Parduzca solutrense superior" añadiendo que "se considera que esa capa $5^{a}$ es una subdivisión arbitraria (a su vez dividida por zonas de color) más o menos equivalente a una parte del conjunto del Nivel IV sedimentológico y/o cultural".

Desde el año 1976 se iniciaron nuevas excavaciones, de las que tan sólo se publicó una breve reseña en la que se efectúa una correlación estratigráfica, entre niveles arqueológicos y las capas en que dividió $F$. Jordá la estratigrafía (Gómez Fuentes y Bécares 1979):

Nivel I. Horizonte superior

Nivel II. Magdaleniense intermedio (conchero de brecha) capa $3^{a}$ rojiza grisácea 
Nivel III. Capa 4a. Magdaleniense inferior. Negro

Nivel IV. Capa $5^{\text {a }}$ parduzca, estrechamente unida al anterior

Nivel V. Capa 6 a posible arcilla estéril

Nivel VI. Capas $7^{\text {a }}$ y $8^{a}$, cenicientas, auriñaciense

Por nuestra parte, al comparar la estratigrafía publicada por Utrilla (1981) -que se basa en la correlación publicada por Gómez Fuentes y Bécares (1979) - con una fotografía del estado actual del perfil de la excavación, tomada en 2012 (Fig. 2), observamos cómo las capas 1 y 2 corresponden al conchero en el que G. A. Clark tomó la muestra; las capas 3 (que no se aprecia en la imagen) y 4 constituyen los niveles magdalenienses (niveles 2 y 3 , respectivamente); la capa 5 (nivel 4), es la de color parduzco que F. Jordá asignó al Solutrense final; y, por último, las capas 6, 7 y 8 corresponden a los niveles auriñacienses. Por otra parte, $y$ en relación con el nivel solutrense documentado en esta cueva, en la fotografía se puede observar en la base del mismo un nivel más negro que F. Jordá refleja en el diario, pero que no individualizó como una unidad aparte del resto de capas, sino que lo consideró como la base de la $5^{\text {a }}$ capa. Esto nos lleva a pensar que este nivel 4 de El Cierro estaría compuesto realmente por 2 subniveles diferentes. A pesar de ello, mantenemos aún un interrogante al respecto de la secuencia estratigráfica, a la espera de la publicación de la estratigrafía definitiva y los datos sedimentológicos de la excavación más reciente.

\section{EL NIVEL 4}

El único estudio de material lítico de este nivel conocido hasta la fecha, es el que realiza Straus (1983), quien indica que la industria lítica del nivel 4 (asignada al Solutrense superior) cuenta con un total de 337 piezas retocadas, entre las que dominan los raspadores, especialmente de los tipos altos. Según este autor, esto estaría en la línea del resto de las colecciones de los yacimientos solutrenses asturianos, que poseen elevados porcentajes de raspadores por contraposición a las colecciones vascas, cuyos índices más altos corresponden a los buriles. También observa una elevada proporción de denticulados, escotaduras y raederas, añadiendo que sólo encontró 3 puntas solutrenses. Para L. G. Straus, un dato significativo sobre la industria lítica del nivel 4 de El Cierro es que, junto con El Castillo, serian los dos yacimientos que más perforadores presentan en los niveles asignados al Solutrense, por contraposición al resto de las colecciones de los yacimientos cantábricos, que poseen porcentajes más bajos.

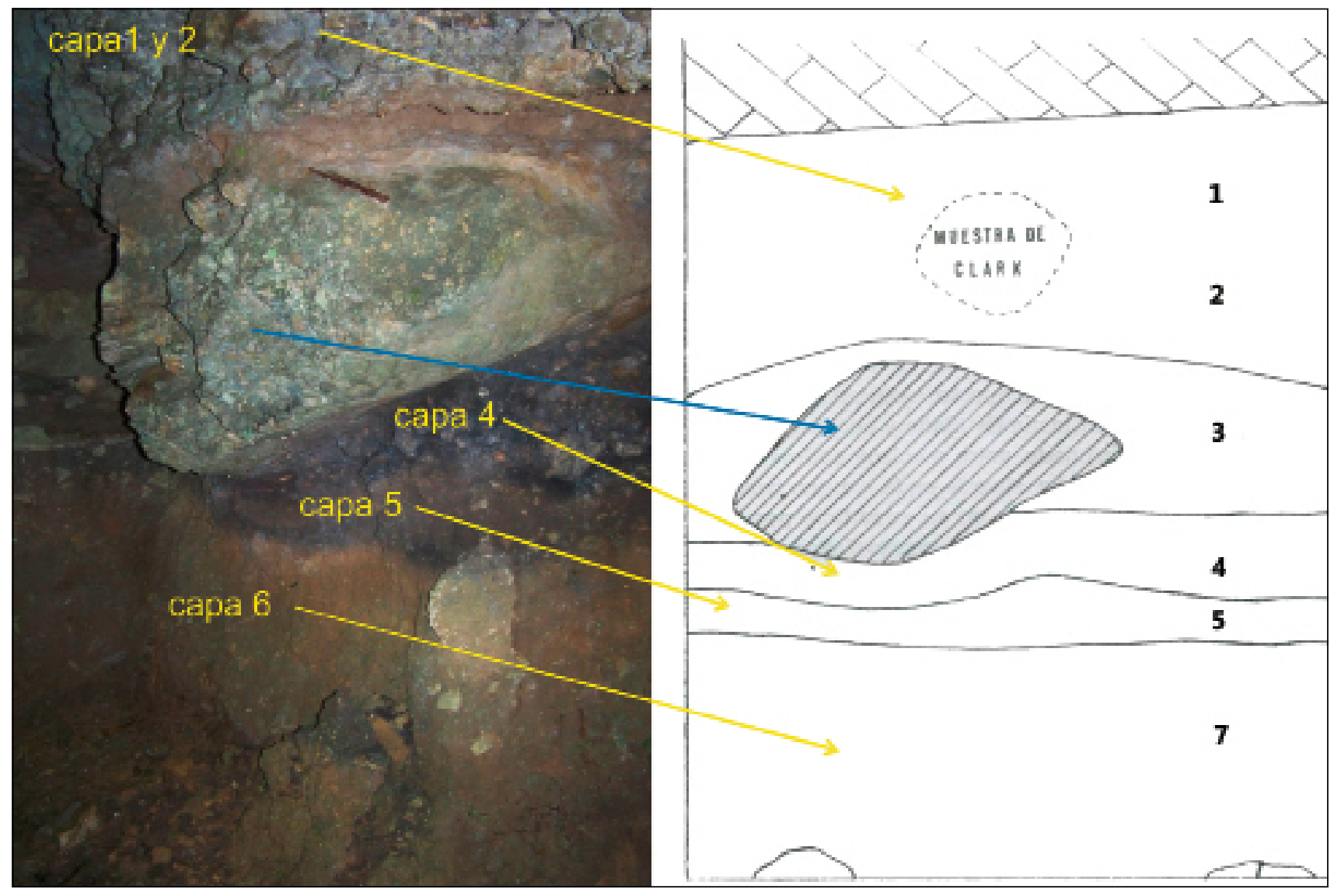

A Figura 2. Correlación de los niveles de la estratigrafía realizada por P. Utrilla (1981) con una fotografía actual. 


\subsection{Materias primas líticas}

Nuestro estudio se centra en primer lugar en el análisis de la materia prima, que en el nivel 4 de El Cierro es predominantemente cuarcita local, en la que han sido realizadas aproximadamente la mitad de las piezas. Tras ésta, el material más representado es la radiolarita en sus variedades gris y roja, seguida por el sílex gris y el chert negro. El resto de materiales tienen escasa representación (Fig. 3).

La mayor parte de las materias primas documentadas en el yacimiento proceden de su entorno inmediato, fundamentalmente de medios aluviales. En la figura 4 podemos observar que el $80 \%$ de los materiales tienen un carácter local; el $4 \%$ es sílex de tipo indeterminado y el $5 \%$ silex desilicificado. El $11 \%$ restante corresponde a materias primas siliceas en las que hemos identificado nódulos de pequeño tamaño y córtex con marcas de impactos en medio fluvial que, por sus características y presencia en otras cuevas cercanas, y su más que probable procedencia de un medio fluvial, hace que también sea posible que se trate de materias primas locales, aunque no se ha podido determinar su origen de una forma fehaciente. Si sumamos estas últimas de posible carácter local a aquellas cuyo origen está constatado como próximo al yacimiento, el porcentaje de materiales de posible filiación local sería cercano al 90\%. Por todo ello, podríamos señalar que las estrategias de captación de materias primas de estos grupos humanos representados en el nivel 4 de la cueva de El Cierro se caracterizan, en líneas generales, por su inmediatez (Fig. 4).

Por lo que respecta a la cuarcita gris, presente en distintas tonalidades y granulometrias, ha sido documentada su presencia en algunos aluviones actuales existentes en los ríos del oriente de Asturias. En concreto, por lo que al cercano río Sella se refiere, se puede localizar a lo largo de todo su cauce.

Intercaladas en las calizas del Carbonifero inferior, atravesadas ya por el Sella desde su cauce alto, se localizan distintas litologías, entre las que aparecen algunos tipos de lutitas, también presentes en el yacimiento. Dentro las importantes series calizas del Carbonifero presentes en la zona, destaca la conocida formación Alba, caracterizada por la caliza griotte y por la presencia en ella de radiolaritas. También por debajo de la formación Alba, tenemos una estrecha franja denominada formación Vegamián, en la que podemos encontrar pizarras litificadas que se denominan liditas (de un color negro intenso muy caracteristico) que también

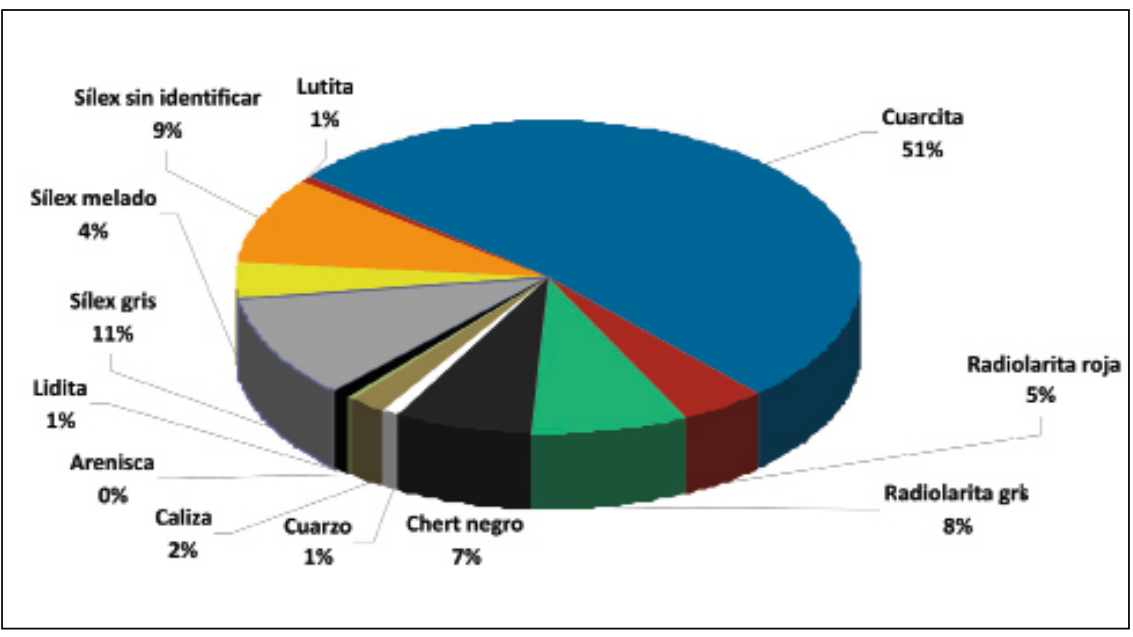

\section{materias primas - El Cierro 4}

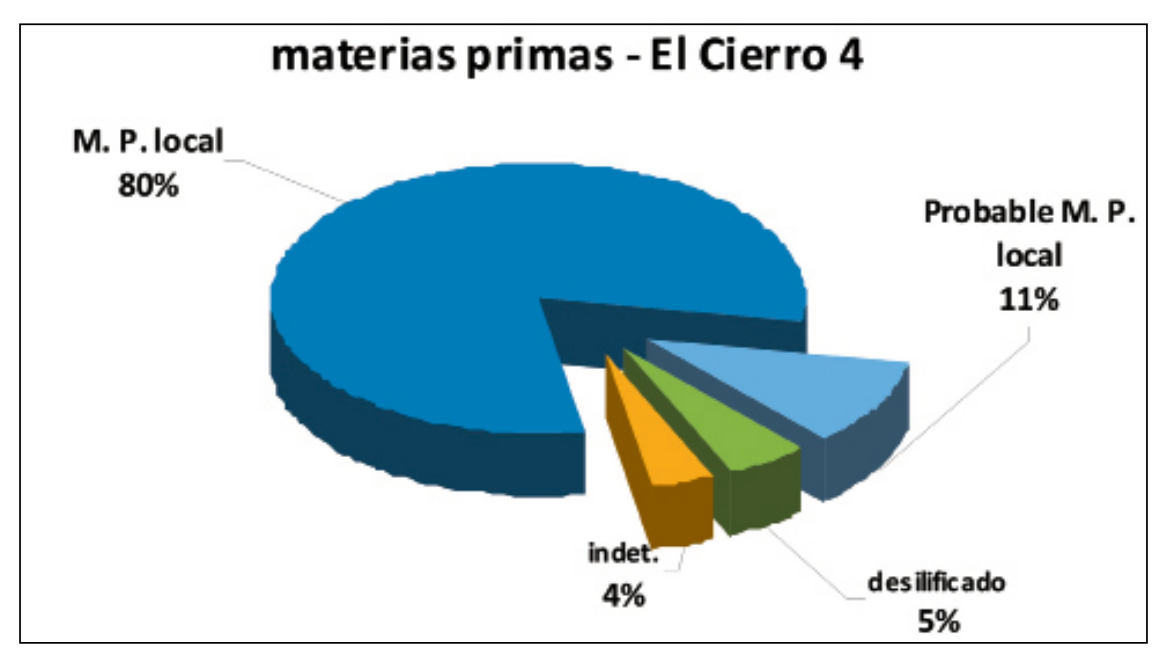

Figura 3. Porcentaje de materias primas documentadas.
4 Figura 4. Porcentajes de materias primas endógenas y exógenas. 
hemos documentado en El Cierro, así como en otros yacimientos del valle como El Buxu. Estas liditas se han venido denominando como sílex negro, el cual hay que diferenciarlo de otra variedad, también presente en el cauce del Sella y en la cueva de El Cierro de manera abundante, que es el denominado chert negro, al que en ocasiones se le ha nombrado como radiolarita negra. El chert negro, como se menciona en otros trabajos relativos a los materiales líticos procedentes de este sector de la cordillera cantábrica (Fuertes et al. 2010) está presente en varias formaciones, algunas de las cuales también son atravesadas por el cauce del río Sella, como las formaciones Barcaliente y Vegamián, por lo que al igual que la radiolarita, también es una litología con afloramientos presentes en la cuenca del Sella. También se ha identificado la presencia de un sílex local, de tipo melado-amarillento y presente en otros yacimientos del oriente asturiano, que se correspondería con el llamado sílex de Piloña localizado en las cercanías de la cueva de El Sidrón (Fortea et al. 2010; Santamaría et al. 2011).

La presencia de todas estas rocas (cuarcita, lutita, radiolaritas y chert) ha sido constatada por nuestra parte en diversos aluviones del río Sella, así como el cuarzo, la arenisca y distintos tipos de caliza que se corresponden con las sucesivas formaciones geológicas que atraviesa el río desde su cabecera en el puerto del Pontón. Aunque están presentes en distintos afloramientos a lo largo del Sella, no hay duda en que la captación de estos recursos líticos, por parte de los grupos prehistóricos, era secundaria, en contextos aluviales. La presencia de las mismas en aluviones actuales, unido a las evidencias y estigmas documentados en las pátinas y córtex que muestra el material arqueológico, así parece confirmarlo.

\subsection{Industria lítica y cadenas operativas}

Tras el estudio que hemos realizado, hemos contabilizado un total 1379 restos líticos entre el material asignado al nivel 4, de los cuales 384 (28\%) son útiles, 85 (6\%) núcleos y 910 (66\%) restos de talla diversos. En el conjunto lítico distinguimos dos cadenas operativas principales, enfocadas a la producción de lascas por un lado y de láminas por otro, siendo la primera con 67 núcleos, mucho más representativa que la segunda, con tan sólo 18 núcleos. Estas dos grandes cadenas operativas, están algo ramificadas, ya que en el caso de la talla laminar, esta se divide en dos tipos; por una parte se obtienen láminas de pequeño formato e incluso laminillas, a partir de núcleos realizados sobre pequeños cantos o fragmentos de sílex, radiolarita o chert. Por otra parte se constata la utilización de lascas como soporte para la extracción de laminillas, aunque estas no se documentan en el registro. En cualquier caso, los núcleos para la obtención de láminas o laminillas representan sólo el 20\%

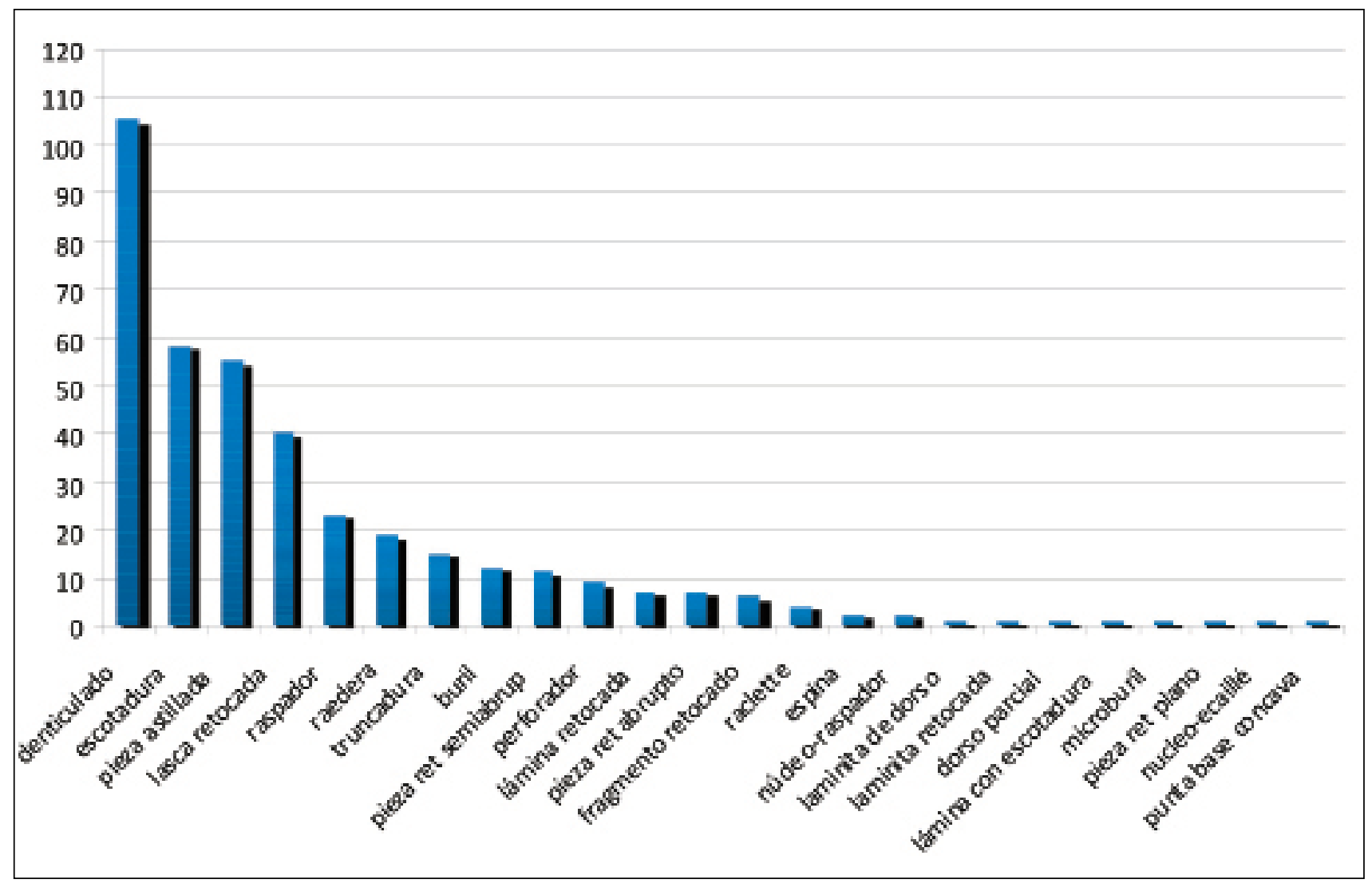

A FiguRA 5. Diagrama de representación tipológica del nivel 4. 


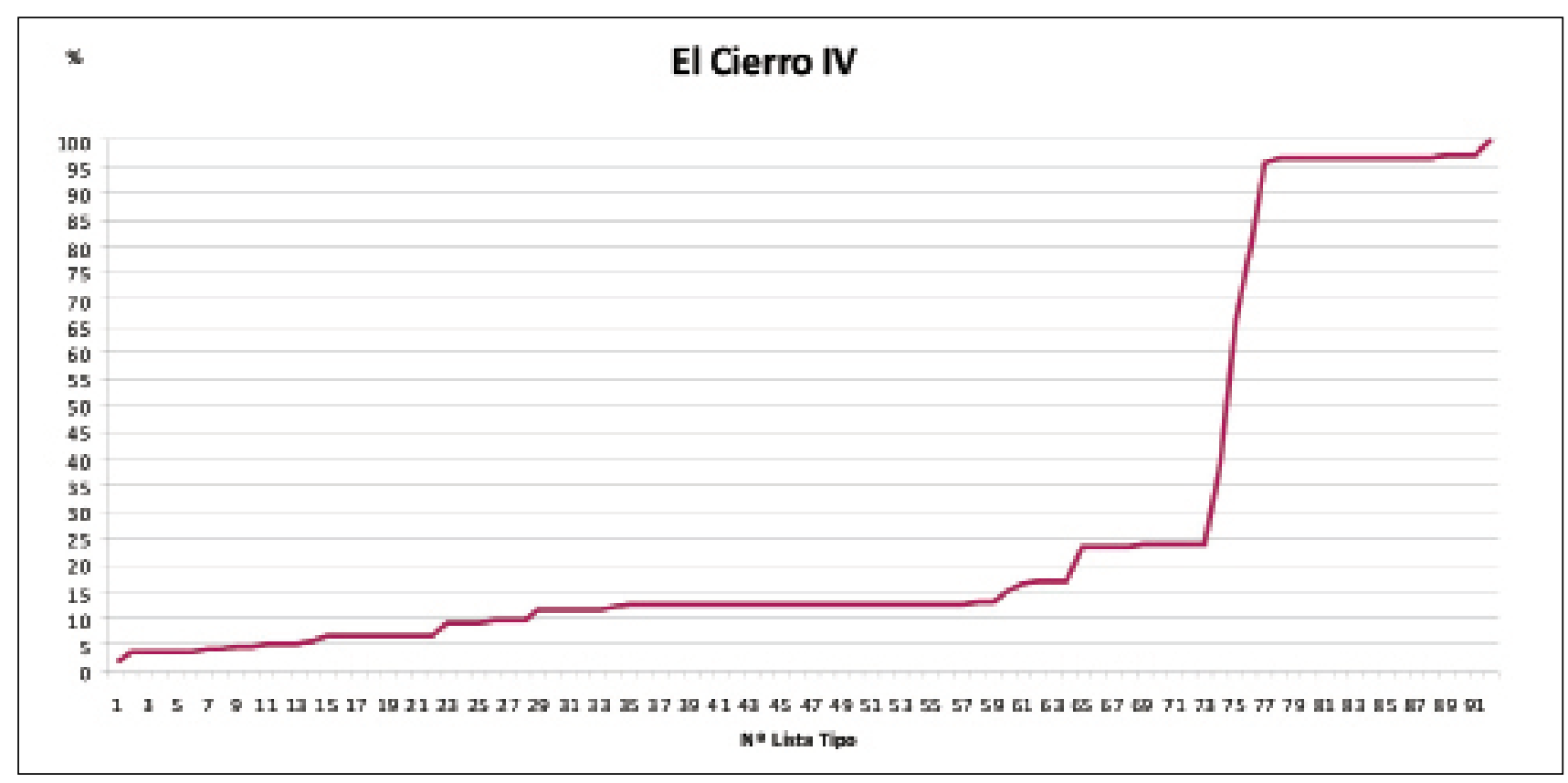

ム Figura 6. Gráfico acumulativo de la serie lítica del nivel 4.

del total de los núcleos, siendo una producción mayoritariamente orientada a la obtención de lascas, ya sea sobre cuarcita o sobre el resto de materias primas. Entre los restos de talla, hemos documentado 72 productos de acondicionamiento (tabletas, flancos, cornisas y crestas) que nos indican la realización de distintas etapas de las cadenas operativas en el propio yacimiento.

La presencia de estos restos, unida a un número elevado de núcleos y lascas, y al hecho de que aproximadamente un tercio del conjunto muestre restos de córtex, parecen indicarnos que las labores de talla se debieron realizar principalmente en la propia cueva.

En cuanto al utillaje, como vemos en los gráficos (Figs. 5 y 6$)$ está dominado por los denticulados $(n=105 ; 27,34 \%)$ escotaduras $(n=58 ; 14,88 \%)$, piezas astilladas $(n=55 ; 14,24 \%)$ y lascas retocadas $(n=19 ; 10,41 \%)$. De este modo, sólo la suma de los tipos denticulados (escotaduras y denticulados) supone el $42,22 \%$ del total del utillaje. Los elementos denominados tradicionalmente como "sustrato" (raederas, lascas retocadas, denticulados y escotaduras) representan el $57,51 \%$ del utillaje lítico, el 71,76\% si añadimos las piezas astilladas, lo que nos muestra un conjunto dominado por este tipo de utillaje (Fig. 7). Los raspadores $(n=26)$ y los buriles $(n=12)$ sólo representan el $9,83 \%$ de los útiles, estando predominantemente elaborados sobre lascas, restos de talla 0 fragmentos laminares reutilizados. En cuanto a los elementos de dorso, tan sólo se ha localizado una hojita. Por el contrario, resulta más significativa, aunque en bajo número, la presencia de 4 raclettes. Igualmente debemos destacar que el 48,3\% del utillaje está elaborado en cuarcita, seguido en importancia del chert y la radiolarita, que suponen el $14,36 \%$ de los elementos retocados.
Por lo que respecta a las piezas con retoque plano, se registran un fragmento proximal de punta de base cóncava, un fragmento de hoja de cara plana y otro fragmento indeterminado con retoque plano; no hemos localizado más evidencias de este tipo de retoque, ni a partir de soportes, ni de restos de talla o preparación.

La presencia mayoritaria de materias primas locales y el desarrollo de cadenas operativas, fundamentalmente de lascas y de manera íntegra, o casi íntegra en el propio yacimiento, nos habla de unos requerimientos técnicos y funcionales sencillos que evidencian cierta inmediatez en el aprovisionamiento, fabricación y uso del utillaje lítico. Esta caracteristica puede tener que ver con la funcionalidad del emplazamiento, pero también parece encajar con la tendencia percibida en otros conjuntos líticos que se sitúan cronoestratigráficamente en la base de las secuencias magdalenienses francesas y también, o en casos de cronología similar, en el Levante peninsular y en la Región Cantábrica, considerados como Magdaleniense arcaico o antiguo (Aura 1995; Aura et al. 2012).

\subsection{Industria ósea}

En cuanto a la industria ósea, según el recuento efectuado más recientemente por Adán (1995) del nivel 4 de El Cierro, se mencionan un total de 26 piezas, entre las que dominan los elementos apuntados, si bien también están presentes los perforados; la lista elaborada por esta autora es la siguiente: 11 piezas apuntadas, 2 de ellas sin acabar; una aguja (más otras 2 posibles); 5 fragmentos de azagayas con secciones rectangular, cuadrangular y circular; un punzón y una punta. En nuestra opinión, alguna de estas piezas 


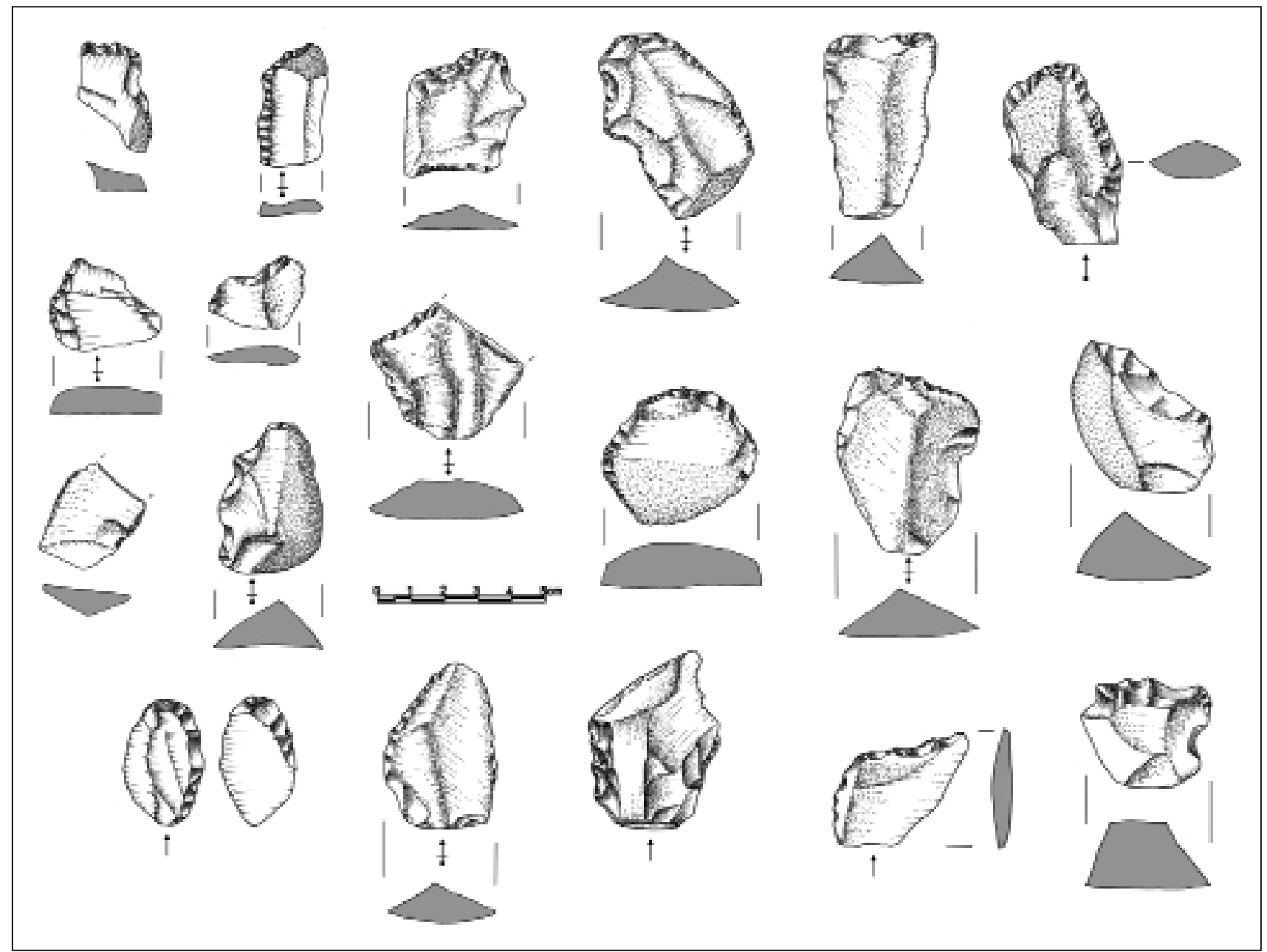

$\Delta$ Figura 7. Industria lítica retocada del nivel 4.

de sección cuadrangular, podría corresponderse más bien con varillas que con azagayas, aunque dado que se trata de fragmentos de pequeño tamaño, no resulta fácil esta identificación. Asimismo, en este nivel, existe un hueso decorado con incisiones rectilineas entrecruzadas, que también ha sido referido en varios trabajos (Corchón 1971 y 1986; Gómez Fuentes y Bécares 1979; Fortea 1990).

L. G. Straus cuando se refirió a la industria ósea del nivel 4, comenta que "Las colecciones de El Cierro incluyen varias puntas de sección cuadrangular (muchas de las cuales están grabadas, así como fragmentos de puntas de sección circular, semicircular y trapezoidal, punzones, un alfiler y una aguja, incisivos de caballo perforados y caninos de ciervo, y un fragmento de costilla pulimentado y perforado. Entre las puntas, hay varias con base en bisel simple y doble, y algunas con aplastamiento central grabado. La presencia de puntas de asta de sección cuadrangular no excluye la posibilidad de una atribución al Solutrense, dado que estas piezas se encuentran en el Solutrense y en el Magdaleniense de Cantabria" (Straus 1974).

Las azagayas de sección cuadrangular y triangular con decoración, se consideran, en líneas generales, un elemento característico del Magdaleniense inferior cantábrico "tipo Juyo" como el que aparece en el nivel 3 de El Cierro. Sin embargo, en algunos casos se ha comentado que este "fósil guía" no sería tal, ya que también estaria presente en niveles del Solutrense final y por lo tanto no serian piezas características a la hora de determinar la atribución de un nivel al Magdaleniense inferior 0 al Solutrense superior, exclusivamente en base a su aparición (Straus 1983; Corchón 1994).

Ahora bien, si ya ha sido superado el esquema cronoestratigráfico imperante hasta los comienzos de la década de los 80, mediante el cual el Solutrense superior estaba seguido del Magdaleniense III, y hoy en día está constatada la existencia de un horizonte del Magdaleniense arcaico/ Badeguliense en el Cantábrico, entre el Solutrense superior y el Magdaleniense inferior, con presencia predominante de azagayas de sección circular y las denominadas "tipo Placard", como sucede en Rascaño, El Castillo o Llonín, y donde también hay presencia de piezas con sección cuadrangularl rectangular ¿Es un criterio válido considerar los elementos de sección cuadrada de El Cierro como de posible filiación solutrense superior por su asociación con tres piezas líticas de retoque plano? 
Tal vez, la explicación pueda hallarse en el empleo de "secuencias antiguas" a la hora de valorar estas cuestiones, y en aspectos complejos de analizar e individualizar, tales como: la mezcla de materiales entre niveles -durante las ocupaciones paleolíticas o incluso durante las excavaciones arqueológicas-; las dinámicas derivadas de la acción humana en los lugares de hábitat (limpiezas, remociones de las superficies, recolección de objetos antiguos, realización de hoyos...). Estas cuestiones, muchas veces no se tienen en cuenta cuando damos por válida la integridad del 100\% del material recuperado en un nivel arqueológico y la contemporaneidad entre todos los elementos del registro. Parece claro que en el caso particular del Cantábrico, los niveles del Solutrense superior con presencia de azagayas de sección cuadrada, son minoritarios con respecto a su abundante presencia en los niveles del Magdaleniense inferior (M. III).

Por ello, habría que explicar convenientemente a qué se debe esta situación: ¿se trata realmente de piezas de factura solutrense, o median problemas tafonómicos en los yacimientos? ¿pudieron existir defectos metodológicos en la recuperación e identificación estratigráfica? ¿se trata simplemente de cuestiones derivadas de la posible mezcla de materiales durante el transcurso de las ocupaciones paleolíticas? ¿algunos de estos niveles que han servido como ejemplo para ilustrar la presencia de azagayas de sección cuadrada en contextos solutrenses, son realmente solutrenses? Finalmente, también hay que ser conscientes que este tipo de secciones pueden hacer su presencia también en un horizonte intermedio, que hace décadas no era tenido en cuenta y hoy en día sí parece estar documentado en algunos yacimientos. Por esta razón el panorama queda más abierto que cerrado, sirviendo igualmente el criterio que atribuye estas piezas al Solutrense superior, tanto para apoyarlo como para refutarlo.

\subsection{Restos de fauna}

Según Straus (1983), los restos faunísticos del nivel 4 de El Cierro que revisó en el Museo en Oviedo, correspondían a 21 ciervos (siendo 3 de ellos juveniles), varios caballos y bovinos, una cabra montés y un jabalí. Para este autor, estos datos indican una especialización en la caza de cérvidos que se vería favorecida por el entorno de la cueva, ya que los cazadores-recolectores de este período pudieron emplear las abundantes dolinas de la zona como cercados/trampas naturales.

Tras la revisión de las colecciones faunísticas del nivel 4 de la Cueva de El Cierro en el Museo Arqueológico de Asturias, podemos comprobar que la colección faunistica está altamente seleccionada en cuanto al número y tipo de partes anatómicas, limitándose a elementos identificables y representativos. En cuanto al análisis de la fauna, realizado por J. Rojo, si atendemos al NMI se puede observar el predominio del ciervo sobre el resto de especies representadas; pero si tomamos como referencia el número de restos, el porcentaje de representación del ciervo crece todavía más, llegando a superar el 90\%.

\subsection{Objetos de adorno}

En cuanto a los elementos de adorno, Álvarez Fernández (2006) menciona la presencia de 4 colgantes en diente (2 en canino de ciervo atrofiado y otros 2 en incisivo de cabaIlo) y una diáfisis de especie no identificada con perforación (¿costilla?). Sin embargo, entre los materiales revisados en el Museo Arqueológico de Asturias para nuestro estudio únicamente hemos podido comprobar la existencia de un colgante realizado en un incisivo de caballo y un fragmento de tibia con una serie de incisiones paralelas.

En relación a los incisivos de caballo documentados en El Cierro es importante destacar que en la región cantábrica únicamente se conocen colgantes de este tipo y en niveles solutrenses, en este yacimiento y en el nivel inferior de Altamira (Breuil y Obermaier 1935). Asimismo, y tal y como indica Álvarez Fernández (2006), aparte de en El Cierro, en el Solutrense cantábrico solamente se encuentran fragmentos óseos transformados en colgantes en los yacimientos de Las Caldas (Sala I. Nivel 10b), Cueto de la Mina (nivel E), La Riera (nivel 13), Chufín (nivel 1) y Aitzbitarte IV (nivel IVb).

\section{DEBATE: EL CIERRO EN LA TRANSICIÓN DEL SOLUTRENSE AL MAGDALENIENSE}

Desde el mismo momento de su excavación, F. Jordá consideró que El Cierro constituía un buen ejemplo para caracterizar la transición del Solutrense al Magdaleniense, ya que al Magdaleniense III (nivel 3) le precedía un nivel con pocas diferencias, en el que aparecian algunas piezas solutrenses. No hay que olvidar que en este momento, tanto Jordá (1960) como González Echegaray (1960) consideraban que el Magdaleniense comenzaba en el Cantábrico con la fase III del sistema de H. Breuil. En consecuencia, y no sin ciertas dudas, F. Jordá decide considerar el nivel 4 como Solutrense superior, ejemplificando de esta manera cómo se produciria la transición entre estas dos culturas, sin apenas rupturas, con una aparente continuidad.

"El único nivel donde hemos podido observar una cierta ligazón entre elementos del Solutrense final cantábrico y el Magdaleniense III ha sido el que recientemente hemos excavado de la Cueva del Cierro (Ribadesella), en donde hemos comprobado la existencia de un fragmento de punta de base cóncava, de otro fragmento de azagaya con aplastamiento central junto con elementos propios y característicos del Magdaleniense III, como son azagayas de segmento de circulo o gibosas, huesos decorados con tectiformes tipo Alta- 
mira y una serie de raspadores y buriles toscos propios del Magdaleniense III cantábrico, como raspadores periformes de dorso alto, que ya hemos analizado en otro lugar. Este nivel de la Cueva del Cierro, todavía inédito, nos demuestra una cierta continuidad cultural dentro de la región cantábrica entre Solutrense y Magdaleniense antiguo, que ya habiamos sospechado e intuido al observar una serie de superposiciones estratigráficas de niveles correspondientes en varias cuevas." (Jordá 1960).

Straus (1983) indica que el Solutrense de El Cierro se parece al Magdaleniense III del Juyo, añadiendo que entre la industria lítica de los niveles del Solutrense y del Magdaleniense inferior de esta cueva apenas hay diferencias a no ser por la ausencia en el nivel magdaleniense de puntas. De esta descripción, deducimos que uno de los criterios sino el principal, que decantaron la asignación del nivel 4 al Solutrense superior, fue la presencia de las citadas puntas de retoque solutrense en este nivel.

Freeman (1987: 31) parece reafirmar las dudas existentes sobre la atribución cronocultural del nivel 4, ya que al referirse al mismo indica lo siguiente "Puesto que el nivel del Cierro mencionado fue considerado como Magdaleniense hasta que Straus identificó 3 puntas solutrenses en él, existe una posibilidad de que esté mezclado". Estas dudas que expresa L. G. Freeman van en dos direcciones, por un lado deja patente que la asignación al Solutrense de este nivel recae en las tres piezas solutrenses, y por otro, plantea una duda sobre la integridad del nivel 4.

Debemos reflexionar sobre todas estas cuestiones, y las opiniones vertidas al respecto, ya que si los niveles 4 y 3 están estrechamente unidos, según la descripción del excavador, siendo prácticamente sucesivos, a día de hoy el marco cronológico propuesto tras analizar el periodo transicional cantábrico, nos habla de un amplio espacio temporal entre el Solutrense superior y el Magdaleniense III (inferior) (Aura et al. 2012). Este espacio temporal no es un vacío cultural, sino que está representado por los inicios del Magdaleniense en el Cantábrico, un Magdaleniense arcaico, anterior al Magdaleniense III, muy discutido y controvertido pero que va poco a poco definiéndose (Sauvet et al. 2008; Aura et al. 2012).

Para ahondar en esta problemática, Bosselin (2000) incluyó El Cierro dentro del conjunto de yacimientos cantábricos que adscribe a lo que denomina Badeguliense tipo A (con pocas raclettes), siendo la primera vez que vemos que se atribuye el nivel 4 de El Cierro a un tecnocomplejo diferente al Solutrense, situado en la base del Magdaleniense, como es el Badeguliense. Para profundizar en estas cuestiones que afectan a la identificación de este horizonte en la región cantábrica, puede consultarse el artículo de D. Álvarez-Alonso y A. Arrizabalaga en este mismo volumen.
En una publicación posterior, Utrilla (2004) al referirse al Magdaleniense inicial cantábrico, considera algunas de las atribuciones de Bosselin (2000) y Bosselin y Djindjian (1999) como buenas, incluyendo El Cierro 4 dentro del Magdaleniense arcaico, en concreto en uno de los dos grupos en que divide este periodo: el caracterizado por la presencia de raclettes. Aunque según nuestra opinión esta división no seria tan neta y El Cierro 4 se podría encuadrar en un genérico "Magdaleniense arcaico", con presencia abundante de utillaje de sustrato ${ }^{2}$ asi como algunas raclettes.

Más recientemente Aura et al. (2012) plantean la posibilidad de que El Cierro pueda incluirse en el grupo de "yacimientos transicionales" entre el Solutrense y Magdaleniense, que han sido definidos como Magdaleniense arcaico para el Cantábrico y como Badeguliense en el Levante, y que muestran muchos paralelos con el Badeguliense francés, como la presencia mayoritaria de materias primas locales y de un llamado "utillaje arcaico". Esta afirmación, con matices, está en sintonía con lo expresado por B. Bosselin, pero no debemos olvidar, que desde la excavación de 1959, F. Jordá ya planteó sus dudas sobre la caracterización del nivel 4 aunque finalmente lo incluyó en el Solutrense superior, refiriéndose a la secuencia de El Cierro como uno de los ejemplos en el que la transición se presenta sin rupturas, haciéndose difícil la determinación entre el Solutrense superior y el Magdaleniense inferior.

En nuestra opinión, pensamos que el nivel 4 de El Cierro es un nivel "no Solutrense" considerando que las argumentaciones en las que se apoyó esta hipótesis han servido tanto para afirmar su filiación solutrense, como sirven hoy en día para refutarlo, por lo que no deben ser elementos determinantes en el análisis. Resumiendo, la cuestión principal parte de la constatación y de la existencia hoy en día de un lapso cronológico amplio entre las últimas ocupaciones solutrenses y las ocupaciones del Magdaleniense inferior (Magdaleniense III) en la región cantábrica. Si este espacio parece estar ocupado por niveles del Magdaleniense arcaico (Aura et al. 2012), el marco interpretativo se amplía, siendo difícil de sostener la atribución del nivel 4 al Solutrense superior a partir de escasos y discutidos elementos, que no tendrían un valor absoluto en la determinación crono-cultural, sobre todo si median problemas tafonómicos, que somos incapaces de evaluar hoy en día y sin una nueva intervención arqueológica.

\section{CONCLUSIONES}

Debemos reflexionar sobre la identidad del nivel 4 y la validez de ciertas asignaciones cronoculturales a partir de restos muy específicos. En consecuencia, nos hacemos la siguiente pregunta: si los útiles de sustrato son abundantes

(2) Lo que P. Utrilla (2004: 257) Ilama toscas piezas macroliticas "musteroides". 
en todos los periodos del Paleolítico superior, y en este nivel son el elemento mayoritario ¿tres piezas de retoque plano bastan para decantar la asignación de dicho nivel al Solutrense? Esto cobra importancia cuando en otros yacimientos cercanos hay constancia de piezas solutrenses en contextos que han sido redefinidos como Magdaleniense arcaico, como así ocurre con los niveles del Solutrense final de La Riera (Straus y Clark 1986) que han sido reinterpretados recientemente y no sin polémica, como Magdaleniense arcaico, a pesar de existir algunos elementos de retoque plano (Sauvet et al. 2008; Aura et al. 2012). La explicación a esta posibilidad -encontrar piezas pertenecientes a un tecnocomplejo cultural en un contexto cronoestratigráfico posterior- es amplia, desde la recolección por parte de grupos magdalenienses de objetos antiguos encontrados en las cuevas habitadas, hasta cuestiones de índole tafonómica como fruto de la superposición de suelos de ocupación, que generan verdaderos palimpsestos y en donde se constatan muchas veces alteraciones o removilizaciones de material como fruto de la reorganización o "limpieza de las zonas de hábitat". Por ello, no debe ser raro pensar que puede ser relativamente normal el que en los llamados "horizontes culturales" que solemos asociar con "horizontes estratigráficos" aparezcan piezas que proceden de contextos no contemporáneos, a veces incluso infrayacentes en los mismos lugares de hábitat, como por ejemplo sucede con el hallazgo de dos puntas de base cóncava con retoque plano, típicamente solutrenses, en los niveles del Magdaleniense inferior de la cueva de La Güelga, en la cuenca alta del Sella (Menéndez y Martínez 1991), donde además, en la base de esta estratigrafía no hay niveles solutrenses (si en otras zonas de la cueva). Algo más evidente es el hallazgo en contextos de finales del Paleolítico superior de elementos claramente discordantes, como son la presencia de cerámicas neolíticas o calcolíticas, que se entiende es debido a la superposición de horizontes culturales y a la remoción de las superficies de ocupación, pero que por ello no invalida la atribución del horizonte paleolítico, ni mucho menos hace que consideremos esas piezas pertenecientes al Paleolítico; esto no es discutido en casos tan claros, pero entre niveles paleolíticos, ahí es más complejo discernir qué puede ser lo propio de un nivel o de otro. Partir de la creencia en entidades estratigráficas "cerradas" y homogéneas, equiparables a horizontes culturales bien acotados y definidos es, sin duda, una cuestión muy problemática y que en absoluto se ajusta a la realidad, ya que existen numerosos matices de indole tafonómica en los que es difícil profundizar, pero en los que es necesario fijarse. Si tenemos un nivel magdaleniense, superpuesto a otro solutrense, por ejemplo no podemos saber si todos los raspadores, buriles, raederas son de un nivel y no del otro, aunque no debemos ignorar la posibilidad de que en el contacto de niveles, se produzcan intercambios y mezclas entre ambos horizontes. Ahora bien, cuando nos encontramos en ese mismo horizonte una pieza característica como son las piezas de retoque plano ¿debemos inmediatamente atribuir todo el nivel al Solutrense? o por el contrario ¿debemos plantearnos la posibilidad antes expuesta y no tomar el tradicional "fósil guía" como una pieza determinante desde un punto de vista excesivamente culturalista a la hora de decantar la atribución del nivel en cuestión? Difícil cuestión de compleja resolución, pero que nos debe abrir el horizonte a la hora de relativizar el valor de determinadas piezas dentro de un conjunto, algo que no nos debe hacer perder de vista otros elementos de análisis, menos llamativos o menos claros, pero igual o más importantes de cara al estudio global.

Tras efectuar este análisis, debemos exponer cuáles son las conclusiones principales a partir de los datos aportados por los materiales:

1. Solo encontramos una hojita de dorso. Puede ser debido a deficiencias en la metodología de excavación (ausencia de materiales inferiores a 1 y 2 $\mathrm{cm}$ entre el material del Museo) o por cuestiones de tipo funcional, relacionado con las actividades llevadas a cabo, donde abunda el uso de materia prima local y de baja calidad para la talla microlaminar. Por otra parte, las hojitas están presentes en el Solutrense superior y en el Magdaleniense inferior, pero vemos que en contextos transicionales que se definen como Badeguliense o Magdaleniense arcaico, se ha mencionado su ausencia o la existencia de índices muy bajos.

2. Por debajo del nivel 4 no tenemos constancia de la existencia de niveles solutrenses, y los únicos elementos típicamente solutrenses son las tres piezas de retoque plano mencionadas. En el contexto lítico no se ha encontrado evidencia alguna de la elaboración de piezas bifaciales o de la realización de retoque plano. Del mismo modo no se han identificado cadenas operativas que nos indiquen la fabricación de utillaje típicamente solutrense.

3. En el conjunto lítico del nivel 4 se han identificado 4 raclettes, que aún no constituyendo un elemento representativo, es porcentualmente similar a la presencia de dorsos, siendo en este caso un descriptor ampliamente mencionado para el Magdaleniense arcaico / Badeguliense (Utrilla 2004; Aura et al. 2012).

4. Con respecto a la industria ósea, en base a los registros existentes en otros yacimientos cantábricos, los mismos argumentos que han sido utilizados para atribuir este material al Solutrense superior, podrian ser igualmente válidos para encajar estas pocas piezas en el Magdaleniense III (periodo al que tampoco creemos que pertenece el nivel 4), con lo cual la industria ósea no resulta ser un elemento determinante para resolver esta cuestión. 
El Cierro 4, parece ser un buen ejemplo de un nivel arqueológico, pobre en materiales y, por lo tanto, en posibilidades de establecer una asignación cronocultural a partir de las industrias. A esto habría que añadir que fue excavado en una época en la que ante la escasa o nula aplicación del C14 y de los análisis paleoambientales y faunísticos, las industrias suponían el único elemento discriminador, y por lo tanto, determinante. Esta cuestión y la existencia de ciertos paradigmas sobre el Magdaleniense cantábrico, que llevaban su inicio en la región a partir del Magdaleniense III, hacian que todo lo que se encontrase inmediatamente por debajo pudiera ser asignado, como en este caso, al Solutrense superior. La existencia de piezas solutrenses en el nivel parece ser trascendente para tal atribución, así como su posición estratigráfica, infrayacente a un nivel del Magdaleniense III.

A lo largo de este trabajo hemos tratado de realizar un análisis crítico de este nivel y su contenido arqueológico, basándonos en las evidencias existentes y en las interpretaciones, manifestaciones y circunstancias que han ido envolviendo al nivel 4 de El Cierro. Hemos realizado un estudio que ha tratado de ser objetivo, no partiendo del presupuesto de que analizábamos un nivel solutrense, sino más bien un análisis de un conjunto lítico cuya interpretación, finalmente, se nos hace difícil como solutrense -o cuanto menos planteamos una duda razonable para aceptar tal extremo-, no porque creamos que muchas de las características expuestas no tengan cabida en dicho tecnocomplejo, sino más bien porque el abanico de posibilidades está más abierto, pudiendo tener cabida este nivel en el Magdaleniense arcaico, a la luz del estado actual de la investigación.
Bajo nuestro punto de vista, la pertenencia de dicho nivel al Solutrense superior es muy cuestionable, no pudiendo aceptarlo sin tener en cuenta también las dudas que nos llevan a plantear otras posibilidades. No creemos oportuno que con este estudio quede cerrada la atribución definitiva de este nivel a un tecnocomplejo o contexto cronocultural concreto, ya que consideramos que eso deberá plantearse 0 determinarse con nuevas intervenciones y analíticas, o con la presentación de los resultados de las excavaciones de los años 70. De todos modos, ante las evidencias presentadas pensamos que, provisionalmente, el nivel 4 de la cueva de El Cierro debe reconsiderarse como un nivel que posiblemente encuentra mejor ubicación en la base de la secuencia magdaleniense cantábrica, lo que se viene denominando Magdaleniense arcaico o inicial -equiparable cronológica y tecnológicamente al horizonte badeguliense identificado en otras regiones- y no en el techo de la secuencia solutrense.

\section{AGRADECIMIENTOS}

Agradecemos al Dr. J. F. Jordá Pardo, el habernos facilitado el diario de campo del profesor F. Jordá Cerdá, sobre sus excavaciones en la cueva de El Cierro. Agradecemos también a J. Rojo los comentarios realizados sobre su estudio de la fauna procedente del nivel IV de la excavación de F. Jordá, aún inédito. Igualmente agradecemos los comentarios y sugerencias de los editores y los revisores de este artículo, que han contribuido a la mejora del texto. Este trabajo ha contado con la financiación del proyecto HAR2010-2013. •

\section{BIBLIOGRAFÍA}

AdÁn Álvarez, G. E. 1995: De la caza al útil. La industria ósea del tardiglaciar en Asturias. Consejeria de Cultura. Principado de Asturias. Oviedo.

AltunA, J. 1972: Fauna de mamíferos de los yacimientos prehistóricos de Guipúzcoa. Munibe 24. Guipúzcoa.

Álvarez Fernández, E. 2006: Los objetos de adorno-colgantes del Paeolítico superior y del Mesolitico en la cornisa cantábrica y el valle del Ebro: una visión europea. Ediciones Universidad de Salamanca. Salamanca.

AURA, J. E. 1995: El Magdaleniense mediterráneo: La Cova del Parpalló (Gandia, Valencia). Trabajos Varios 91. Servicio de Investigaciones Prehistóricas. Diputación Provincial de Valencia. Valencia.

Aura, J. E., Tiffagom, M., Jordá Pardo, J. F., Duarte, E., Fernández de la Vega, J., Santamaría, D., Rasilla, M. De La, Vadillo, M. y PÉREZ, M. 2012: "The Solutrean-Magdalenian Transition: a viewfrom the southwest". Quaternary International 272-273: 75-87.

Bernaldo de Quirós, F. (1982: Los inicios del Paleolítico Superior Cantábrico. Museo Nacional y Centro de Investigación de Altamira. Monografía 8. Ministerio de Cultura. Santander.

BreUIL, H. y ObermaleR, H. 1935: The Cave of Altamira at Santillana del Mar, Spain. Junta de Cuevas de Altamira, the Hispanic Society and the Academia de la Historia. Madrid.

BosSELIN, B. y DJINIAN, F. 1999:" Une révision de la séquence de La Riera (Asturies) et la question du Badegoulien cantabrique". Bulleti $n$ de la Société Préhistorique Française 96 (2): 153-173.
Cabrera Valdés, V., Arrizabalaga Valbuena, A., Bernaldo de Quirós, F. y Maillo FernÁndez, J. M. 2004: "La transición al Paleolítico superior y la evolución de los contextos auriñacienses (50.000 - 27.000 BP)". En M. Fano (ed.): Las sociedades paleolíticas de la región cantábrica Kobie (Serie Anejos) 8: 141-208.

ClaRK, G. A. 1976: El Asturiense cantábrico. Instituto de Estudios Asturianos. Madrid.

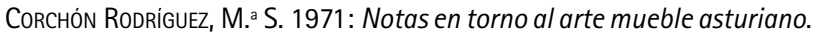
Universidad de Salamanca. Salamanca.

- 1986: El arte mueble Paleolítico Cantábrico. Contexto y análisis interno. CIMA 16. Santander.

- 1994: "Arte mobiliar e industria ósea solutrense en la Cornisa Cantábrica". En M. de la Rasilla (ed.): El Solutrense en la Península Ibérica. Férvedes 1: 131-148.

- 1999: "Solutrense y Magdaleniense del oeste de la cornisa cantábrica: dataciones $\mathrm{C} 14$ (calibradas) y marco cronológico". Zephyrvs LII: 3-32.

FoRTEA, J. 1990): "El arte paleolítico en Asturias". Historia de Asturias 1. Prensa Asturiana S. A. Oviedo: 65-84.

Fortea, J., Rasilla, M. de la y SAntamaría, D. 2007: "Solutrense y Magdaleniense en Asturias". La Prehistoria en Asturias. Un legado artístico único en el mundo:389-414.

Fortea, J., Rasilla, M. de la; Santamaría, D., Martinez, L., Duarte, E. y FerNÁNDEZ DE LA VEGA, J. 2010: "El Paleolitico superior en Asturias en los albores del siglo XXI". En X. Mangado (ed.): El Paleolítico superior 
peninsular. Novedades del siglo XXI. Homenaje al Profesor Javier Fortea: $271-289$.

Fuertes, M. a N., Neira, A., Gómez, F., Alonso, E. y Fernández, E. 2010: "Caracterización de las materias primas líticas del yacimiento mesolítico de El Espertín (León)". En S. Domínguez-Bella, J. Ramos, J.M. Gutiérrez y M. Pérez (eds.): Minerales y rocas en las sociedades de la Prehistoria: 169-184.

Gómez Fuentes, A. y BÉcARES, J. 1979: "Un hueso grabado de la cueva de El Cierro (Ribadesella, Asturias)". XV Congreso Nacional de Arqueología: 83-94.

Hoyos Gómez, M. y RASILLA VIVES, M. DE LA 1994: "Dataciones C14 del Paleolítico superior del abrigo de Cueto de la Mina (Posada de Llanes, Asturias)". Trabajos de Prehistoria 51 (2): 143-147.

JoRdÁ CERDÁ, F. 1959: Guía del Museo Arqueológico. Diputación Provincial de Asturias. Oviedo.

- 1960: "El complejo cultural Solutrense-Magdaleniense en la región cantábrica". Primer Symposium de Prehistoria de la Península Ibérica. Septiembre 1959, Diputación Foral de Navarra. Institución "Príncipe de Viana", Pamplona: 1-22.

- 1963: "El Paleolítico superior cantábrico", Saitabi XIII: 3-22.

- 1975: "Sobre ideomorfos de haces de línea y animales sin cabeza". Symposium international sur les religions de la Prehistoire. Valcamonica Symposium, 18-23 septembre 1972: 73-80.

- 1977: "Prehistoria". Historia de Asturias. Ayalga. Salinas.

Menéndez Fernández, M. y Martínez Villa, A. 1991: "Excavaciones arqueológicas em La cueva de La Güelga. Campañas de 1989-1990". Excavaciones Arqueológicas en Asturias 1987-1990: 75-80.

RASILLA VIVES, M. DE LA (COORD.)1994: El Solutrense en la Península Ibérica. Férvedes 1.

RAsilla VIVES, M. de La y SANTAmaría, D. 2005: "Tecnicidad y territorio: Las puntas de base cóncava del Solutrense cantábrico". Munibe 57: 149-158.
Santamaria, D., Rasilla, M. De la; Martinez, L. y Tarriño, A. 2011: "Las herramientas y su interpretación cultural y económica". La cueva de El Sidrón (Borines, Piloña, Asturias). Investigación interdisciplinar de un grupo neandertal: 137-146.

Sauvet, G., Fortea, J. Fritz, C. y Tosello, G. 2008: "Crónica de los intercambios entre los grupos humanos paleolíticos. La contribución del arte para el periodo 20000-12000 años BP". Zephyrvs LXI: 35-59.

StRAUS, L. G. 1974: "Notas preliminares sobre el Solutrense de Asturias". BIDEA 82: 483-504.

- 1975: "¿Solutrense o Magdaleniense inferior cantábrico? Significado de las diferencias". BIDEA 86: 781-791.

- 1979: "Notas teóricas sobre el Solutrense de Asturias". BIDEA 9697: 473-484.

- 1983: El Solutrense vasco cantábrico. Una nueva perspectiva. Museo Nacional y Centro de Investigación de Altamira. Monografía 10. Santander.

Straus, L.G. y Clark, G. A. 1986: La Riera Cave. Stone Age hunter-gatherer adaptations in Northern Spain. Anthropological Research Papers 36. Ariona State University.

Straus, L. G., Bernaldo de Quirós, F., Cabrera, V. y Clark, G. A. 197778: "Solutrean Chronology \&t Lithic Variability in Vasco-Cantabrian Spain". Zephyrvs XXVIII-XXIX: 109-112.

UtRILLA, P. 1976: "La región asturiana durante los inicios del Magdaleniense". BIDEA 88-89: 801-853.

- 1981: El Magdaleniense inferior y medio en la costa cantábrica. Museo Nacional y Centro de Investigación de Altamira. Monografía 4, Santander.

- 2004: "Evolución histórica de las sociedades cantábricas durante el Tardiglaciar: El Magdaleniense inicial, inferior y medio (16.50013.000 BP)". En M. Fano (ed.): Las sociedades paleolíticas de la región cantábrica. Kobie (serie anejos) 8: 243-274. 
